\title{
FORMAÇÃO CIDADÃ E PRÁTICAS EDUCATIVAS: \\ PERSPECTIVAS DE ANÁLISE DE PROFESSORES
}

\author{
CITIZEN TRAINING AND EDUCATIONAL PRACTICES: \\ ANALYSIS OF TEACHERS ' PERSPECTIVES
}

\section{FORMACIÓN DEL CIUDADANO Y LAS PRÁCTICAS EDUCATIVAS: ANÁLISIS DE LAS PERSPECTIVAS DOCENTES}

CALLAI, H. C. TOSO, Cláudia E. I. (orgs). Diálogos com professores: cidadania e práticas educativas, Editora Unijuí, Ijuí, 2015.

Carina Copatti ${ }^{\mathrm{I}}$

Alana Rigo Deon ${ }^{\text {II }}$

\footnotetext{
${ }^{\text {I }}$ Universidade Regional do Noroeste do Estado do Rio Grande do Sul, Rio Grande do Sul - Brasil. Email: c.copatti@hotmail.com

${ }^{\text {II }}$ Universidade Regional do Noroeste do Estado do Rio Grande do Sul, Rio Grande do Sul - Brasil. Email: alanadeon@gmail.com
}

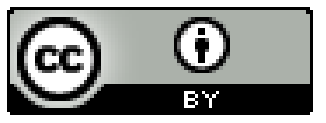

Educação: Teoria e Prática, Rio Claro, SP, Brasil - eISSN: 1981-8106

Está licenciada sob Licença Creative Common 
Esta resenha traz reflexões sobre o livro Diálogos com professores: cidadania $e$ práticas educativas, resultado da produção anual (2015) do grupo de pesquisa Ensino $e$ Metodologias em Geografia e Ciências Sociais, coordenado pela professora Dr. ${ }^{a}$ Helena Copetti Callai, inserido no Programa de Pós-Graduação em Educação nas Ciências da Universidade Regional do Noroeste do Estado do Rio Grande do Sul - UNIJUÍ.

Os artigos resultam das inquietações do grupo de pesquisadores que é composto por acadêmicos, docentes que atuam em universidades e na educação básica. As pesquisas desenvolvidas pelo grupo trazem em seu enlace ideias que foram debatidas e construídas em conjunto. Esse movimento enriquece os trabalhos, pois são vistos por olhares de professores com diferentes formações, emergindo uma produção de conhecimentos de modo crítico, reflexivo e conciso teoricamente.

A cidadania constitui dimensão interlocutora para o aprofundamento teórico das discussões realizadas nos encontros e também nas pesquisas desenvolvidas por cada um dos componentes do grupo. Nesse sentido, conforme Callai e Toso (2015, p. 16) o livro expõe "a articulação com que o grupo vem desenvolvendo [seus trabalhos] nos últimos anos, considerando o fazer de cada sujeito e, atravessados pela temática da cidadania”. Assim, os autores, no decorrer dos artigos, apresentam preocupação com o olhar crítico e hermenêutico, e trazem a formação para a cidadania como tema que perpassa todos os textos, considerando, também, os desafios dos profissionais docentes na formação dos alunos como cidadãos comprometidos com a realidade do mundo, a fim de buscar possibilidades de transformá-la.

O texto inicial da obra é de Helena Callai e tem como título "A questão da cidadania nas séries iniciais". A autora trata da possibilidade de pensar a cidadania nas séries iniciais da escolaridade buscando superar a ideia dos círculos concêntricos, os quais consideram que para entender o mundo o estudante precisa partir do simples, imediato, próximo, para o mais complexo, linearmente. No entanto, o mundo atual é desafiador e exige um ensino que propicie ao estudante ferramentas intelectuais para que se emancipe socialmente. Por isso, a autora aponta que o trabalho escolar pautado na escala de análise geográfica ${ }^{1}$ (que considera o espaço absoluto, relativo e relacional) é uma das formas de interpretar para compreender o mundo atual, buscando superar a fragmentação do ensino. O processo de ensino pautado sobre

\footnotetext{
${ }^{1}$ Esse conceito geográfico busca superar a perspectiva dos círculos concêntricos, no qual a abordagem dos conteúdos é feita do mais simples para o mais complexo. O que impossibilita a leitura e compreensão do mundo. Atribuições estas do ensino de geografia.
} 
este viés permite o acesso a uma cidadania plena e uma globalização mais humana, a começar pelo ensino de Geografia na escola.

O texto de Elisabete Andrade "Formação Continuada de Professores/as como possibilidade de e para cuidar de si e dos outros" discute sobre a complexidade do processo de formação continuada de professores no Brasil refletindo sobre os dilemas desse processo. $\mathrm{O}$ primeiro dilema é demarcado pela dificuldade na definição (conceitual e na legislação educacional brasileira) do que seja a formação continuada e quais são as modalidades consideradas pertinentes às demandas educativas. Outro dilema é a implicação pessoal de quem escolhe atuar nessa profissão, e isso se desdobra no nível de conhecimento da área disciplinar na qual atua e o conhecimento da própria profissão. Sob esse olhar, a autora traz alternativas para esse processo referenciada no conceito foucaultiano de "Cuidado de si" $\mathrm{e}$ dos outros, de modo que a formação continuada de professores possa se articular às demandas geradas na e pela prática pedagógica.

Adriana Andreis, em seu texto "Ser professor: Uma (Auto) Aprendizagem Provisória" faz uma reflexão sobre a constituição do ser professor, tendo a sua prática profissional como pano de fundo para a escrita do texto. O movimento da reflexão é iniciado quando uma aluna exclama que a partir de suas aulas aprendeu Geografia. A professora então questiona o que ela teria aprendido? Dessa forma, Adriana inicia, pelo exercício da escrita, em formato de crônica, um processo de auto-reflexão-indagação sobre a prática docente, fazendo um diálogo com os paradigmas denominados por Marques (1992) de metafisico, modernidade e neomodernidade. Esses paradigmas servem como possibilidade de reflexão na ação e para a ação do professor. Sob este viés, a formação pode ser vista como uma (auto) aprendizagem provisória, que tem a pesquisa e a extensão como atividades inerentes à prática do professor.

“A pesquisa como princípio pedagógico: Protagonismo e Interdisciplinaridade" é o texto de Martin Kuhn e Gilvane Zilli. Apresenta uma discussão teórico-prática sobre a pesquisa enquanto possibilidade de construção do conhecimento escolar no Ensino Médio. O texto é estruturado a partir das discussões das Políticas Educacionais, especialmente as Diretrizes Curriculares para o Ensino Médio (2012), que entendem a pesquisa como um recurso metodológico que possibilita a construção de novos conhecimentos e a formação de sujeitos pesquisadores, críticos e reflexivos. Dessa forma, é apresentada uma proposta de

${ }^{2}$ Conceito elaborado e discutido pelo filósofo Michael Foucault. 
Copatti, C.; Deon, A. R.

pesquisa, nomeada como pesquisa escolar - planificação em teia - que permite traçar um caminho não linear na investigação de conceitos, fatos, características e fenômenos que se constituem objeto do conhecimento escolar. A pesquisa sob esta perspectiva, abre possibilidades de diálogo interdisciplinar e permite que o aluno conheça o próprio processo do aprender, tornando-o significativo para a sua vida. Nesse sentido, a pesquisa contribui para que o aluno se torne protagonista na construção do seu conhecimento.

Maria Elena Neves da Silva no texto "A instituição de ensino superior na formação inicial para a educação especial" apresenta a pesquisa realizada em sua dissertação de mestrado na qual refletiu sobre a fragilidade das questões educativas, principalmente no que concerne ao processo de formação inicial de professores, tendo como principal eixo de discussão a educação especial. Para endossar essa discussão, a autora traz experiências de sua vida privada (como mãe de uma menina deficiente visual) e de sua prática cotidiana como professora, apontando a complexidade do processo de inclusão, tanto para as escolas como para as IES. Mesmo com o amparo de políticas educacionais a questão da inclusão ainda é um desafio para a prática cotidiana do professor que, muitas vezes, não tem uma formação que o possibilite compreender o aluno com deficiência ou mesmo que viabilize a aprendizagem dos alunos da educação especial.

"A possibilidade de humanizar o atendimento fisioterapêutico" de Tânia Regina Warpechowski aborda as práticas de fisioterapia. A autora reflete sobre as mudanças ocorridas nas últimas décadas nas concepções e nos usos da fisioterapia entendida como uma atividade reparadora e reabilitadora. Discussões recentes sobre a temática ampliam esta compreensão para uma perspectiva humanizada de atendimento aos pacientes. A explanação é embasada numa pesquisa empírica sobre o conhecimento do estudante de fisioterapia em relação ao atendimento humanizado, e o cotidiano de trabalho dos profissionais públicos e privados. A reflexão demonstra que o atendimento humanizado contribui para a valorização da qualidade do atendimento fisioterapêutico, compreendendo o significado da vida e a valorização da dimensão humana do paciente.

Maristela Moraes e Sergio Claudino L. Nunes, no texto “A guerra dos Guaranis existiu?", lançam um olhar sobre os manuais escolares portugueses e brasileiros, em relação a como apresentam a guerra guaranítica. Mais do que responder à questão central, os autores debatem acerca do olhar que os dois países lançam com relação a um confronto que partilham 
em sua história. No decorrer do texto discutem o silenciamento ou pouco aprofundamento das questões que envolvem os conflitos entre colonizadores e indígenas guaranis na produção historiográfica portuguesa, e como isso se dá, tanto no currículo escolar secundário e básico $\left(10^{\circ}\right.$ ano e $3^{\circ}$ ano), quanto nos Programas de Geografia daquele país. Em relação aos manuais brasileiros, ao analisar obras literárias, destacam a literatura como espaço para investigações históricas. Também consideram o modo como a história dos Sete Povos das Missões é tratado em obras sobre o ensino de literatura. Para isso, os autores analisam dois livros escolares do Ensino Médio e, novamente percebem que há o silenciamento desta temática. Desse modo, constatam que a invisibilidade das lutas guaraníticas não acontece apenas na história dos colonizadores, mas também na história do Brasil. É perceptível, conforme os autores, o silenciamento tanto entre os historiadores, quanto nos manuais escolares, perpassando o ensino de história, geografia e língua portuguesa, que têm o desafio de constituir espaço de reflexão e independência em relação aos discursos dominantes.

No artigo "Conectando a Geografia escolar na cibercultura: banco internacional de objetos educacionais e escola digital", Ana Giordani reflete sobre a cibercultura na docência e as nuvens ${ }^{\mathrm{i}}$ como possíveis ferramentas de aprendizagem na contemporaneidade. A autora apresenta os objetos de aprendizagem na geografia escolar em conexão com a vida do aluno que está "online", como novas alternativas para o ensino e aprendizagem. Neste contexto, defende que as práticas pedagógicas não se sustentam sem a interação com o aluno, atentando para as características destes numa sociedade líquida e globalizada. Tal processo requer uma geografia comprometida com a mudança também da escola, e que os professores saibam por quais espaços reais e virtuais os alunos circulam. Para tanto, considera a necessidade de utilizar os Objetos de Aprendizagem na geografia escolar, iniciando pela imersão do professor ao conhecimento de sua utilidade e suas potencialidades. Posteriormente, por meio da "Escola digital", contato com as plataformas (repositórios) disponibilizados para ampliar a aprendizagem, busca favorecer a colaboração, a interação e a autoria de professores e alunos no processo de construção do conhecimento.

No texto "Criança, espaço, tempo e construção do conhecimento", Claudia Ilgenfritz Toso apresenta inquietações de sua vivência enquanto docente na formação de professores, e instiga reflexões sobre a importância de considerar a criança como sujeito do processo de aprendizagem. A autora compreende a educação infantil como etapa principal na formação do sujeito e contribui no sentido de pensar a infância como categoria social e a criança como 
sujeito ativo, autor e ator social, como projeto de futuro, ou seja, como a continuidade da vida. Cláudia sustenta a importância de considerar as peculiaridades da criança, sendo essencial o contato com a família, através de entrevista para melhor conhecê-la. Considera que o desenvolvimento social da criança se dá, em grande parte, no ambiente escolar, no contato com os colegas e com as provocações do professor. Dessa forma, faz-se necessário ampliar situações intencionais, planejadas para ampliar as noções espaço-temporais das crianças. Apresenta várias situações que podem ser exploradas com o intuito de estimular as crianças a vivenciar o espaço e o tempo na escola, construindo conceitos para a aprendizagem significativa desde a infância.

"Diferentes ou iguais, podemos viver juntos? Uma experiência sobre a diferença na escola”, é apresentado por Edinaldo Enoque S. Junior. O autor traz contribuições para pensar a escola, no contexto pós-moderno, como espaço fecundo de observação e estudo sobre a transformação do mundo. Espaço este em que diferentes grupos estão imersos e no qual precisam seguir as mesmas regras, num processo de interação e respeito que flui para além da localidade, ampliando-se para o ciberespaço. $\mathrm{O}$ autor considera que, a priori, o professor seria o profissional que estaria mais aberto à aceitação do outro e dos jovens, inseridos na interconectividade contemporânea. Procura compreender se, de fato, a escola está aberta ao outro, a partir de um estudo com alunos de $8^{\circ}$ ano, na disciplina de História, por meio de experiências sobre diversidade no ambiente escolar. $\mathrm{O}$ autor entende a educação como espaço para debates sobre a globalização em diferentes aspectos, dentre eles no que diz respeito à identidade e à relação com o outro. Nesse contexto, a escola emerge como articuladora entre a fragmentação da identidade e o enrijecimento identitário, e atenta para a necessidade de mudança de atitude dos professores em relação aos problemas que a humanidade enfrenta.

Em "Geografando dentro e fora da escola: reflexões sobre trabalho de campo", Camila B. da Silva e Cristiane X. Hagat tratam do trabalho de campo como estratégia para olhar e compreender o mundo, a fim de significar a aprendizagem no contexto contemporâneo. As autoras consideram o trabalho de campo como situação pedagógica essencial para a leitura da paisagem e como possibilidade de intervenção no espaço. A partir de um projeto desenvolvido pelas autoras em setembro de 2014 no Chile, denominado "Geografiando tu escuela, desde el barrio a la ciudad" exploram "a paisagem do bairro como espaço próximo do aluno, local como ele constrói suas relações" e, posteriormente, apresentam uma proposta de leitura da paisagem para a escola básica no Brasil, por meio de vivências e práticas 
pedagógicas, ao mesmo tempo que realizam propostas de leitura do bairro, do espaço urbano e das paisagens. As autoras consideram o trabalho de campo como meio para a pesquisa; este precisa ser orientado pelo professor e seguir alguns percursos, tendo em vista seu caráter de experiência espaço-temporal. Ao defender que a leitura do mundo, numa concepção freireana, compreende a leitura do espaço antes mesmo da leitura das palavras, destacam os diferentes sentidos que atuam na leitura da paisagem. O "olhar" além de ver, transpõe as aparências, em um processo que atenta para o conhecimento prévio do aluno, com o intuito de que conceba o lugar como significado para ele.

Cristhian Moreira Brum, no artigo "Taller em Havana: uma experiência latina de intervenção social" discorre sobre sua experiência inicial com a prática do Taller, vivenciada em Havana-Cuba, 2014, no Taller de Arquitetura "S.O.S ciudades". Compõe, como professor convidado internacional, um grupo de professores talleristas e de acadêmicos do curso de arquitetura e urbanismo de algumas instituições de seis países da América Latina, a saber: Brasil, Chile, Paraguai, Uruguai, Argentina e Peru. Nessa experiência, o grupo foi desafiado a realizar uma intervenção na Baía de Havana por meio da metodologia do Taller, que se constitui como uma possibilidade de professores e alunos, pelo olhar coletivo e colaborativo, participar de uma experiência pedagógica de intervenção em uma determinada área, aliando o saber prático e a cidadania. Esta metodologia interdisciplinar atende ao propósito de projetar o espaço urbano para os indivíduos, para atender suas necessidades de acessibilidade, conforto e inserção social. Nessa experiência foram a campo 20 grupos com 18 alunos, além dos professores e representantes de órgãos governamentais, com local específico para as discussões e seminários, tendo disponíveis os materiais necessários para os estudos que culminavam diariamente com uma palestra de encerramento. $\mathrm{O}$ autor destaca que essa prática torna o futuro arquiteto e urbanista qualificado para intervir no espaço e integrar-se com a realidade, além de proporcionar, pela percepção coletiva, uma reflexão acerca dos problemas de arquitetura e de urbanismo detectados durante o estudo do lugar. Nessa prática todos ganham: talleristas, docentes, discentes, além de atender as necessidades dos habitantes do lugar com novas possibilidades de intervenção no espaço urbano.

Dessa forma, os textos que compõem a obra trazem os diferentes olhares, leituras e percepções sobre a educação e o ensino vivenciados pelos integrantes do grupo de pesquisa Ensino e Metodologias em Geografia e Ciências Sociais. Essas vivências/ experiências foram refletidas e sistematizados através da escrita, como uma possibilidade de alargar os 
Copatti, C.; Deon, A. R.

conhecimentos dos integrantes do grupo e assim aprimorar suas práticas educativas nos contextos em que se inserem. Nesse sentido, "escrever para pensar" e também dialogar, como afirma Marques (2006) tem orientado os trabalhos e estudos que são desenvolvidas por esse grupo de pesquisadores.

\section{Referências:}

CALLAI, H. C.; TOSO, C. E. I. (orgs). Diálogos com professores: cidadania e práticas educativas, Editora Unijuí, Ijuí, 2015.

MARQUES, M. O. Escrever é preciso o princípio da pesquisa. 5. ed. Ijuí: Editora Unijui, 2006.

Recebido em: 21/06/2017

Aprovado para publicação em: 20/02/2018

Publicado em: 13/12/2018

\footnotetext{
'Nuvens a que a autora se refere "são tecnologias que colocam nossos alunos em conexão com modos de ser, de viver e aprender contemporaneamente." Nesse sentido, ainda esclarece que nuvem é utilizada como metáfora para socializar o movimento da provisoriedade das reflexões realizadas. (Giordani, 2015: 150)
} 